\title{
Denise Aigle. « La figure de Moïse dans quelques textes mystiques persans médiévaux »
}

\section{Nelly Amri}

\section{(2) OpenEdition \\ 1 Journals}

\section{Édition électronique}

URL : http://journals.openedition.org/abstractairanica/46635

DOI : 10.4000/abstractairanica.46635

ISBN : 1961-960X

ISSN : 1961-960X

Éditeur :

CNRS (UMR 7528 Mondes iraniens et indiens), Éditions de l'IFRI

Référence électronique

Nelly Amri, « Denise Aigle. "La figure de Moïse dans quelques textes mystiques persans médiévaux » », Abstracta Iranica [En ligne], Volume 37-38-39 | 2018, document 2, mis en ligne le 30 décembre 2018, consulté le 28 septembre 2020. URL : http://journals.openedition.org/abstractairanica/46635 ; DOI : https://doi.org/10.4000/abstractairanica.46635

Ce document a été généré automatiquement le 28 septembre 2020

Tous droits réservés 


\title{
Denise Aigle. « La figure de Moïse dans quelques textes mystiques persans médiévaux »
}

\author{
Nelly Amri
}

\section{RÉFÉRENCE}

Denise Aigle. « La figure de Moïse dans quelques textes mystiques persans médiévaux » in Denise Aigle \& Françoise Briquel Chatonnet (dir.). Figures de Moïse. Paris : Éditions de Boccard, 2015, p. 321-350

1 L'islam, comme d'ailleurs les deux autres religions monothéistes, a réservé une place privilégiée à Moïse : messager, "Interlocuteur de Dieu ", figure du cheminant, du disciple mais aussi figure paradigmatique de l'ivresse mystique pour les spirituels musulmans. Les récits coraniques sur Moïse au Sinaï et sur son voyage initiatique avec Khadir, ont donné lieu à de riches interprétations symboliques pour exprimer la relation des mystiques persans avec le divin, de même que la figure de Moïse a été utilisée dans un but didactique dans des mathnawis de 'Ațtāar et de Rūmī afin de délivrer un enseignement spirituel. C'est ce que Denise Aigle montre dans cet article fouillé et dense, émaillé de nombreux extraits de textes en vers et en prose, et articulé en deux temps. Pour Ḥallāj dans son commentaire de l'épisode du Buisson ardent, Moïse est le modèle du "progressant» (sālik) qui, pour aller vers la Réalité suprême, doit «s'expatrier " par des « voies étroites »; la manifestation de Dieu à travers le buisson ardent devient symbole de l'union mystique. Le récit coranique de la rencontre de Moïse avec Dieu est devenu l'un des thèmes de la poésie persane, notamment dans les ghazals de Hâfiz. De nombreuses allusions à l'épiphanie sur le Sinaï se trouvent dans le Dìvwān de 'Aț̣āâr, ainsi que le lan taranī » qui exprime la soif du divin. Rūmī présente le désir de la vision divine de Moïse comme un acte d'amour. Pour Rūzbihān Baqlī Shīrāzĩ dans son Kashf al-asrār Moïse est son premier modèle, mais il est strictement subordonné au prophète Muhammad; d'autres passages évoquent l'épisode de la 
théophanie au Sinaï. Les mystiques extatiques, comme Rūzbihān, ont tenté de rompre symboliquement cette inaccessibilité en plongeant dans l'«océan divin» pour atteindre, tout comme Moïse au Sinaï, l'ivresse mystique. Dans tous ces épisodes relatifs au Sinaï, la figure de Moïse est perçue de manière positive : il représente un modèle de sainteté extatique. Il n'en va pas de même dans l'histoire coranique de Moïse et de Khaḍir qui s'apparente plutôt à un voyage à épreuves et qui a également donné naissance à d'innombrables commentaires. Ce périple fut souvent vu comme le prototype de la relation entre disciple (murid) et maitre spirituel (murshid), relation dans laquelle, traditionnellement, le disciple doit accepter sans questions la guidance du maître. Moïse, cependant, y apparaît très légaliste et incapable de comprendre les actions de son guide. Pour Shahrastānī, influencé notamment par Sulamī et les premiers maîtres, Moïse habite dans le royaume du doute et des vagues suspicions tandis que Khadir, son compagnon de voyage, demeure dans le royaume de la certitude. Bien qu'il soit doté d'un cœur sincère, Moïse éprouve des difficultés à dépasser les formes extérieures de la religion.

Dans la deuxième partie de l'article, Moïse est mis en scène avec divers personnages pour délivrer un enseignement. Prophète législateur, il représente l'homme de la Loi religieuse, et est bien souvent imperméable à l'amour divin incarné par des personnages peu instruits ou «fous en Dieu». Ces derniers expriment une intense soif de Dieu, mais en des termes qui peuvent parfois choquer un esprit dogmatique, incarné ici par Moïse, dont le savoir était d'ordre exotérique. L'image de Moïse n'est pas pour autant totalement négative. Il incarne aussi l'âme sincère qui aspire à la sainteté. Le prophète législateur n'est pas la seule image qui est donnée de Moïse par 'Aț̣ār et Rumī. Il est présenté comme "l'Amant ('āshiq) passionné » qui, tout entier submergé par l'amour divin, jette à terre les tables de la Loi pour les briser.

Bref, c'est une image riche, contrastée et complexe, en somme un Moïse "profondément humain » que les textes mystiques persans, mais aussi la littérature exégétique, révèlent.

\section{AUTEURS}

\section{NELLY AMRI}

Université de la Manouba, Tunis 